\title{
Archipel
}

ARCHIPEL Études interdisciplinaires sur le monde insulindien

\section{3 | 2017}

Varia

\section{Maître Tace (Amá « Père ») Roman social philippin, 1929, Liwayway}

(«Aurore », hebdomadaire)

\section{Marlies Salazar}

Traducteur : Jean-Paul G. Potet

\section{OpenEdition}

\section{Journals}

Édition électronique

URL : http://journals.openedition.org/archipel/423

DOI : 10.4000/archipel.423

ISSN : 2104-3655

\section{Éditeur}

Association Archipel

\section{Édition imprimée}

Date de publication : 6 juin 2017

Pagination : 229-230

ISBN : 978-2-910513-74-0

ISSN : 0044-8613

\section{Référence électronique}

Marlies Salazar, «Maître Tace (Amá «Père ») Roman social philippin, 1929, Liwayway

("Aurore », hebdomadaire) », Archipel [En ligne], 93 | 2017, document 93, mis en ligne le 01 juin 2017 consulté le 25 septembre 2020. URL : http://journals.openedition.org/archipel/423 ; DOI : https:// doi.org/10.4000/archipel.423 


\section{COMPTES RENDUS}

Lázaro Francisco, Maître Tace (Amá «Père ») Roman social philippin, 1929, Liwayway (" Aurore », hebdomadaire). Manille, Traduit directement du tagal par Jean-Paul G. Potet, Lulu Press, Inc. Raleigh, NC, USA, 2016, 352 pp., ISBN: 978-1$326-57955-5$

Cette traduction d'un des romans les plus importants des Philippines du $\mathrm{xx}^{\mathrm{e}}$ siècle est un petit chef-d'œuvre, autant par la qualité de la traduction que par l'analyse linguistique et ethnologique. Pour en apprécier la portée, il faut absolument lire les NDT (Notes du Traducteur) en bas de la page qui livrent toutes sortes d'explications utiles.

L'auteur Lazaro Francisco fut longtemps oublié par l'élite anglophone de Manille, parce qu'il avait vécu en province et publié en tagal et non en anglais. Mais il connaît depuis quelque temps une sorte de renaissance et a été déclaré National Artist à titre posthume en 2009.

Ayant terminé la traduction dès 1992 , le traducteur a vécu une véritable odyssée avant de pouvoir publier le roman en français, en partie parce que la délégation philippine à l'Unesco n'avait aucune documentation sur cet auteur. Finalement, il a pu le publier en impression à la demande en 2016.

Lázaro Francisco (1898-1980) a passé sa vie dans la province de Nueva Ecija en tant que petit employé de la fonction publique. N'ayant pas eu la possibilité de faire des études supérieures, il n'a jamais vraiment appris l'anglais. Par contre, il a remarquablement cultivé sa langue maternelle et en est devenu l'un des plus grands auteurs $\mathrm{du} \mathrm{xx}^{\mathrm{e}}$ siècle. Il a publié onze romans, sept nouvelles, deux adaptations théâtrales et une pièce de théâtre.

Il connaissait très bien la vie des pauvres dans une société encore semi-féodale et, dans ses romans sociaux, il dénonce l'exploitation des paysans par les gros propriétaires. 
Amá (Père) traduit ici par son nom honorifique « Maître Tace » est un vieux paysan très respecté dans son village, mais persécuté par le propriétaire de la terre dont il est l'un des tenanciers. Il essaie d'éviter les conflits et fait tout pour que son fils Delphin puisse faire des études supérieures. Il est un père exemplaire, d'où le titre de l'original.

Le roman nous emmène dans un village idyllique appelé " Eaublanche » qui se trouve près d'une chute d'eau. Mais ce cadre est trompeur : sous la nature tropicale se cache beaucoup de misère. Quand une compagnie de jeunes gens, invités par le propriétaire, arrive pour un pique-nique à la campagne au frais du pauvre Tace, les villageois regardent les citadins avec un mélange d'envie et d'admiration. Et bientôt des conflits éclatent entre les jeunes gens et entre le propriétaire et les paysans. Je ne veux pas aller dans les détails. Il faut se laisser entraîner par l'atmosphère du livre. À la fin, il y aura un dénouement incroyablement romantique.

La langue classique utilisée par l'auteur est très éloignée du tagal actuel et rend la lecture difficile pour le lecteur moderne, qui est habitué à un langage plus familier avec moins d'expressions de politesse. Cela se reflète aussi dans la version en français. Le traducteur utilise une langue très recherchée.

Le roman est suivi par des articles sur l'histoire et la situation linguistique des Philippines, ainsi que par des glossaires pour les personnages, lieux, et plantes tropicales cités. Quel travail remarquable !

Marlies Salazar 